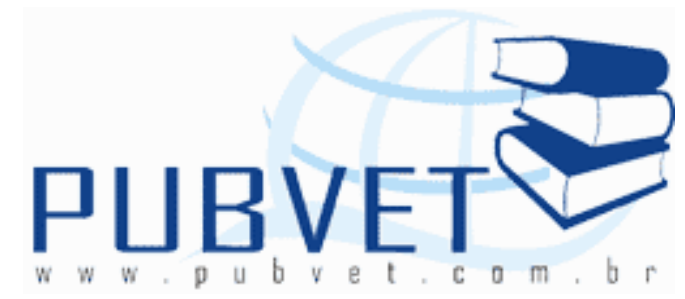

PUBVET, Publicações em Medicina Veterinária e Zootecnia.

\title{
Digestão e absorção de carboidratos pelas aves
}

Juliana Klug Nunes ${ }^{1 *}$, Cristiéle Lange Contreira ${ }^{2}$, Amauri Tavare ${ }^{3}$, Sara Lorandi ${ }^{4}$, Cibele Medeiros dos Santos ${ }^{5}$, Tiago Araújo Rodrigues ${ }^{5}$

${ }^{1}$ D.Sc., Médica Veterinária - Universidade Federal de Pelotas

2 Engenheira Agrônoma, Mestranda Programa de Pós-Graduação em Zootecnia - Universidade Federal de Pelotas

${ }^{3}$ Graduando em Zootecnia - Universidade Federal de Pelotas

${ }^{4}$ Médica Veterinária, Mestranda Programa de Pós-Graduação em Zootecnia Universidade Federal de Pelotas

${ }^{5}$ Graduando em Agronomia - Universidade Federal de Pelotas

*Autor para Correspondência. E-mail: julianaklug@yahoo.com.br

\section{Resumo}

Objetivou-se revisar bibliograficamente a digestão e a absorção dos carboidratos pelas aves. O fornecimento de dietas ricas em carboidratos, logo após a eclosão das aves, aumenta a concentração de glucose no sangue e aumenta a disponibilidade de proteínas para a formação de tecidos corporais e para o desenvolvimento da ave. A secreção de algumas enzimas, como a da amilase pelo pâncreas e a sua ativação no intestino delgado se desenvolve ao longo da vida das aves. Da digestão dos carboidratos são resultantes açúcares simples que podem participar da construção de outras substâncias ou serem metabolizados com produção de água, dióxido de carbono e energia. A maioria dos produtos resultantes do metabolismo de 
NUNES, J.K. et al. Digestão e absorção de carboidratos pelas aves. PUBVET, Londrina, V. 7, N. 17, Ed. 240, Art. 1588, Setembro, 2013.

carboidratos é absorvida por transporte ativo e os não digeridos sofrem fermentação no intestino grosso. O metabolismo, que envolve a secreção de enzimas, influencia a disponibilidade energética dos alimentos. A idade da ave, a composição, a forma física, o processamento e as interações com outros nutrientes influenciam a digestibilidade dos carboidratos.

Palavras-chave: Açúcares simples, Animais não ruminantes, Digestibilidade, Energia, Enzimas, Fermentação.

\section{Digestion and absorption of carbohydrates by poultry}

\section{Abstract}

The objective was to review bibliographically digestion and absorption of carbohydrates by poultry. The provision of high carbohydrate diets, shortly after hatching of poultry increases the concentration of glucose in the blood and increases the availability of protein for the formation of body tissues and for the development of the bird. The secretion of some enzymes such as amylase and its activation by the pancreas into the small intestine develops over the life of the poultry. From the resulting digestion of carbohydrates are the simple sugars that can participate in the building or other substances being metabolized to produce water, carbon dioxide, and energy. Most of the products resulting from the metabolism of carbohydrates is absorbed by active transport and undigested undergo fermentation in the large intestine. The metabolism involving enzyme secretion, influence fuel availability of food. The bird age, composition, physical form, processing and interactions with other nutrients influence the digestibility of carbohydrates.

Keywords: Simple sugars, Non-ruminant animals, Digestibility, Energy, Enzymes, Fermentation. 
NUNES, J.K. et al. Digestão e absorção de carboidratos pelas aves. PUBVET, Londrina, V. 7, N. 17, Ed. 240, Art. 1588, Setembro, 2013.

\section{Introdução}

Os carboidratos ou hidratos de carbono são compostos orgânicos que contém carbono, hidrogênio e oxigênio na sua molécula $\left(\mathrm{CH}_{2} \mathrm{O}\right) \mathrm{n}$, sendo o índice $\mathrm{n}$ maior do que três (NUNES, 1998).

Eles se dividem em açúcares solúveis ou extrativos não nitrogenados (ENN) onde se encontram os monossacarídeos (xilose, ribose, arabinose, glucose, galactose, manose), dissacarideos (sacarose, lactose, maltose, celobiose), trissacarídeos (rafinose) e polissacarídeos (xilanos, arabanos, amido, celulose, dextrinas, pectinas) e em insolúveis onde estão as fibras detergentes neutra e ácida (BERTECHINI, 2006).

Os ENN apresentam digestibilidade em torno de 60 a $90 \%$ e a fibra bruta que representa os carboidratos estruturais celulose e hemicelulose possui baixa digestibilidade para os não ruminantes (VIEIRA et al., 2000).

O amido é o polissacarídeo de armazenamento de origem vegetal mais importante, está presente em altos percentuais na constituição da batata, da mandioca e de cereais como milho, sorgo, arroz, milheto, triticale, e representa a principal fonte de energia para os animais não ruminantes (ALAVI, 2003).

Ele é formado por um polímero de glucose, em ligações a-glicosídicas, que possui $10-30 \%$ de amilose e $70-90 \%$ de amilopectina como principais constituintes (NUNES, 1998; LEHNINGER et al., 1995). Por exemplo, na batata doce o teor de amilose no amido varia de 19,1 a 27,0\% (COLLADO \& CORKE, 1999; HOOVER, 2001).

A amilose consiste de cadeias longas, retas unidas por ligações a-1,4 e a amilopectina é formada por cadeias lineares em ligações a-1,4 com pontos de ramificações entre cada 24 a 30 moléculas de glucose, e nesses pontos as ligações glicosídicas são do tipo a-1,6 (LEHNINGER et al., 1995; GONZÁLES \& SILVA, 2003).

Nos grãos de cereais, o amido é armazenado na forma hidratada, ou seja, na forma de glucose $\left(\mathrm{C}_{6} \mathrm{H}_{12} \mathrm{O}_{6}\right)$ e ao ser tratado termicamente a 
NUNES, J.K. et al. Digestão e absorção de carboidratos pelas aves. PUBVET, Londrina, V. 7, N. 17, Ed. 240, Art. 1588, Setembro, 2013.

amilose é dissolvida e a amilopectina mantém sua estrutura, desta forma há a formação de amido resistente o que dificulta a hidrólise pela amilase e consequentemente reduz a digestibilidade do nutriente (BERTECHINI, 2006).

\section{Digestão e absorção de carboidratos}

O crescimento das aves pode ser afetado pela quantidade e qualidade da ração e da água, pela área de superfície do trato gastrointestinal (TGI), pelo nível de enzimas pancreáticas e intestinais, enfim pela digestibilidade dos nutrientes (DIBNER et al., 1998).

O TGI, já nos primeiros dias de vida das aves, passa por alterações morfológicas e fisiológicas de preparação para o aproveitamento dos ingredientes da ração (MOZDZIAK et al., 2002). Logo, com o aumento da idade das aves a eficiência de digestão e absorção aumenta, ocorrendo ajuste na taxa de passagem do alimento pelo TGI (SIBBALD, 1979).

De quatro a 10 dias após a eclosão, o consumo de ração aumenta em torno de três vezes e a taxa de passagem pelo TGI diminui em 30\% (NOY \& SKLAN, 1995) o que favorece o contato das enzimas digestivas ao alimento e consequentemente melhora o aproveitamento dos nutrientes (NOY \& SKLAN, 1996).

De acordo com Vieira et al. (2000), as aves ao nascerem passam da dependência nutricional de lipídeos e proteínas do saco vitelino para a de carboidratos dos ingredientes da ração, isso quer dizer que após eclodirem as aves são capazes de digerir carboidratos, entre eles o amido (MORAN Jr., 1985; CHOTINSKY et al., 2001), sendo que a amilase pancreática no $18^{\circ}$ dia de incubação já está ativa e sua completa capacidade para a digestão do amido ocorre aos quatro dias de vida das aves (UNI et al., 1995; CHOTINSKY et al., 2001).

Noy \& Sklan (1995) verificaram que o amido é digerido em $85 \%$ aos quatro dias de idade das aves e que posteriormente os incrementos são pequenos. 
NUNES, J.K. et al. Digestão e absorção de carboidratos pelas aves. PUBVET, Londrina, V. 7, N. 17, Ed. 240, Art. 1588, Setembro, 2013.

A disponibilidade da energia do metabolismo de carboidratos é dependente da idade, uma vez que a secreção da amilase pelo pâncreas e a sua atividade no intestino delgado são baixas no início da vida das aves (AKIBA \& MURAKAMI, 1995).

Segundo Longo et al. (2005) os frangos de corte em fase pré-inicial aproveitam 98,4\% da energia proveniente da glucose, e em idade adulta o aproveitamento é maior. De acordo com Duke (1996), a capacidade máxima de absorção da glucose pelas aves ocorre nos primeiros sete dias de idade e após diminui.

O fornecimento de dietas ricas em carboidratos, logo após a eclosão das aves, promove maior concentração de glucose no sangue e queda na atividade da glucose-6-fosfatase, indicando redução da gliconeogênese o que disponibiliza proteínas para a formação de tecidos corporais e para o desenvolvimento da ave (DONALDSON \& CHRISTENSEN, 1991; VIEIRA et al., 2000).

Após a ingestão dos carboidratos, estes são umedecidos pela saliva o que facilita a digestão (DUKE, 1996). Jerrett \& Goodge (1973) relatam que a amilase salivar está presente somente na saliva de gansos. Por outro lado, Duke (1996) descreve que em aves domésticas a amilase foi encontrada na saliva, mas pelo pouco tempo que o alimento permanece na boca a digestão que ocorre é pequena.

Os autores Maier et al. (2010) consideram que a amilase presente na saliva das aves participa da conversão do amido em açúcares mais simples.

Por verificar a digestão da sacarose no inglúvio de galinhas, Pritchard (1972) concluiu que nele pode ocorrer digestão de carboidratos. Noy \& Sklan (1995) também encontraram açúcares solúveis no inglúvio declarando que a absorção é mínima.

A amilase presente no inglúvio da galinha pode originar-se da própria mucosa, das glândulas salivares, do alimento ingerido, das bactérias ou dos conteúdos regurgitados do duodeno (PHILIPS \& FULLER, 1983; DUKE, 1996). 
NUNES, J.K. et al. Digestão e absorção de carboidratos pelas aves. PUBVET, Londrina, V. 7, N. 17, Ed. 240, Art. 1588, Setembro, 2013.

A digestão dos glicídios pelos não ruminantes começa pela boca onde está presente a a-amilase salivar ou ptialina (GONZÁLES \& SILVA, 2003), que hidrolisa as ligações glicosídicas a-1,4, com a liberação de maltose e oligossacarídeos. Contudo, a a-amilase salivar não contribui significativamente para a hidrólise dos polissacarídeos, devido ao breve contato entre a enzima e o substrato (MOTTA, 1989). Após o metabolismo continua no intestino delgado onde ocorre significativamente 0 processo digestivo dos carboidratos (GONZÁLES \& SILVA, 2003).

A a-amilase pancreática ou a-1,4-glicano hidrolase decompõe as ligações glicosídicas $a-1,4$ e produz maltose como produto principal e dextrinas, ou seja, oligossacarídeos contendo em média oito unidades de glucose com uma ou mais ligações glicosídicas a-1,6. Certa quantidade do dissacarídeo isomaltose também é formado (MOTTA, 1989; VAN der MAAREL et al., 2002).

Já a $\beta$-amilase e glicoamilase ou amiloglicosidase atacam os resíduos externos de glucose da amilose e da amilopectina produzindo maltose e glucose, respectivamente. A $\beta$-amilase hidrolisa exclusivamente as ligações a-1,4 e a glicoamilase hidrolisa também as ligações glicosídicas a-1,6, porém mais lentamente (NOROUZIAN et al., 2006).

A hidrólise final da maltose e dextrina é realizada pela maltase e dextrinase presentes na superfície das células epiteliais do intestino delgado (MOTTA, 1989; GONZÁLES \& SILVA, 2003). Conforme descrito por Chotinsky et al. (2001) é no lúmen e na membrana borda em escova do intestino delgado que agem as dissacaridiases específicas que hidrolisam os sacarídeos a monossacarídeos.

Além da maltase e da dextrinase, outras enzimas também atuam na superfície das células intestinais, entre elas estão a isomaltase que hidrolisa as ligações $a-1,6$ da isomaltose, a sacarase que rompe as ligações $a, \beta-1,2$ da sacarose em glucose e frutose, a lactase que fornece glucose e galactose pela hidrólise das ligações $\beta-1,4$ da lactose (MOTTA, 1989; GONZÁLES \& SILVA, 2003). 
NUNES, J.K. et al. Digestão e absorção de carboidratos pelas aves. PUBVET, Londrina, V. 7, N. 17, Ed. 240, Art. 1588, Setembro, 2013.

Assim sendo, da digestão dos carboidratos são resultantes açúcares simples que podem participar da construção de outras substâncias ou serem metabolizados com produção de água, dióxido de carbono e energia (BERTECHINI, 2006).

Nos cecos também há traços de amilase e a absorção de glucose também ocorre nesse segmento do intestino das aves (SAVORY \& MITCHELL, 1991).

Foi verificado por Mateos \& Sell (1980) que a taxa de passagem de açúcares simples pelo TGI de frangos de corte em fase pré-inicial é mais rápida do que a do amido.

Portanto, a digestibilidade de açúcares simples é menor que a do amido, indicando que as características metabólicas existentes em cada fase de desenvolvimento podem afetar o valor energético dos alimentos e da energia metabolizável da dieta (VIEIRA et al., 2000).

Além da influência da idade das aves sobre a digestibilidade do amido há também o aspecto físico-químico do polissacarídeo, a relação amilose/amilopectina, o seu grau de cristalinidade, a forma física, o tipo de processamento do amido e as suas interações com os demais constituintes do alimento (SKRABANJA \& KREFT, 1998). Segundo Bertechini (2006) o amido apresenta digestibilidade superior a 95\%.

A absorção dos produtos resultantes do metabolismo dos carboidratos ocorre por transporte ativo e passivo, sendo mais de $80 \%$ por transporte ativo e os açúcares solúveis maltose, sacarose e lactose são absorvidos na forma de glucose e os carboidratos não digeridos são fermentados no intestino grosso (BEITZ \& ALLAN, 1996).

Bertechini (2006) especifica que a absorção da maioria dos monossacarídeos ocorre, principalmente no duodeno, por transporte ativo com interconversão a glucose na parede do intestino delgado, com exceção da frutose que tem sua absorção realizada por difusão facilitada.

Depois de absorvidos os carboidratos podem seguir as rotas metabólicas da glicólise, glicogenólise, glicogênese, gliconeogênese, ciclos 
NUNES, J.K. et al. Digestão e absorção de carboidratos pelas aves. PUBVET, Londrina, V. 7, N. 17, Ed. 240, Art. 1588, Setembro, 2013.

da pentose fosfatase e de Krebs, lipogênese ou lipólise. Já os não digeridos sofrem fermentação no intestino grosso com a formação de ácidos graxos voláteis que podem ser absorvidos ou excretados. Dos carboidratos absorvidos a maior fração é metabolizada a lipídeos (BERTECHINI, 2006).

\section{Conclusões}

O metabolismo, que envolve a secreção de enzimas, influencia a disponibilidade energética dos alimentos.

A idade da ave, a composição, a forma física, o processamento e as interações com outros nutrientes influenciam a digestibilidade dos carboidratos.

\section{Referências}

AKIBA, Y.; MURAKAMI, $\mathrm{H}$. Partioning of energy and protein during early growth of broiler chicks and contribuition of vitteline residues. In: WORLD POULTRY SCIENCE CONFERENCE, 1995, Antalia, Turkey. Proceedings... Antalia: World Poultry Science Symposium, 1995. p.46-52.

ALAVI, S. Starch research over the years. Food Research International, v.36, p.307-308, 2003.

BEDFORD, M.R. Mechanisms of action and potential nutritional benefits from feed enzymes. In: _. Proceedings of Feed Enzymes - Realizing their potential in corn/soya based poultry diets. 1998. p.12-26.

BEITZ, D.C.; ALLAN, R.S. Digestão e absorção. In: Dukes Fisiologia dos

Animais Domésticos. $11^{a}$ ed. Rio de Janeiro: Editora Guanabara Koogan S.A., 1996. p.325-330.

BERTECHINI, A.G. Nutrição de Monogástricos. Ed. UFLA, Lavras, MG, 2006, 303 p.

COLLADO, L.S; CORKE, H. Heat-moisture treatment effects on sweet potato starches differing in amylose content. Food Chemistry, v.65, p.329-346, 1999.

CHOTINSKY, D.; TONCHEVA, E.; PROFIROV, Y. Development of dissacharidases activity in the small intestine of broiler chickens. British Poultry Science, v.42, p.389-393, 2001.

DIBNER, J.J.; KNIGHT, C.D.; IVY, F.J. The feeding of neonatal poultry. World's Poultry Science Journal, v.5, p.36-42, 1998.

DONALDSON, W.E.; CHRISTENSEN, V.L. Dietary carbohydrate level and glucose metabolism in turkey poults. Comparative Biochemistry and Physiology, v.98, p.347-350,1991. 
DUKE, G.E. Digestão nas aves. In:

Dukes Fisiologia dos Animais Domésticos. $11^{\mathrm{a}}$ ed. Rio de Janeiro: Editora Guanabara Koogan S.A., 1996. p.317-323.

GONZÁLES, F.H.D.; SILVA, S.C. da. Bioquímica Clínica de Glicídeos. In:

Introdução a Bioquímica Veterinária. Porto Alegre: UFRGS, 2003, p.153-209.

HOOVER, R. Composition, molecular structure, and physicochemical properties of tuber and root starches: a review. Carbohydrate Polymers, v.45, n.3, p.253-267, 2001.

JERRETT, S.A.; GOODGE, W.R. Evidence for amylase in avian salivary glands. Journal of Morphology, v.139, p.27-46, 1973.

LeHninger, A.L.; NELSON, D.L.; COX, M.M. Princípios de Bioquímica. $2^{a}$ ed. São Paulo: Sarvier, 1995, 839p.

LIMA, U. A.; AGUARONE, E.; BORZANI, W.; SCHMIDELL,W. Biotecnologia Industrial: Processos fermentativos e enzimáticos. $1^{\text {a }}$ ed., São Paulo: Editora Edgard Blucher Ltda, v.3, 2001, 288p..

LONGO, F.A.; MENTEN, J.F.M.; PEDROSO, A.A.; FIGUEIREDO, A.N.; RACANICO, A.M.C.; GAIOTTO, J.B.; SORBARA, J.O.B. Carboidratos na dieta pré-inicial de frangos de corte. Revista Brasileira de Zootecnia, v.34, n.1, Viçosa, jan./fev. 2005.

MAIER, J.C.; NUNES, J.K.; PEIXOTO, R.R. Hidratos de carbono. In: alimentação animal. $3^{a}$ ed. Pelotas: Editora e Gráfica/UFPel, 2010, p.54-64.

Nutrição e

MATEOS, G.G.; SELL, J.L. True and apparent metabolizable energy value of fat for laying hens: Influence of level use. Poultry Science, v.59, p.369-373, 1980.

MORAN JR., E.T. Digestion and absortion of carbohydrates in fowl and events through perinatal development. Journal of Nutrition, v.115, p.665-674, 1985.

MOTTA, V.T. Metabolismo dos carboidratos. In:

Bioquímica Clínica: métodos e interpretações. 2a ed. Porto Alegre: Editora Médica Missau, 1989. p.143-188.

MOZDZIAK, P.E.; WALSH, T.J.; MCCOY, D.W. The effect of early posthatch nutrition on satellite cell mitotic activity. Poultry Science, v.81, p.1703-1708, 2002.

NOROUZIAN, D.; AKBARZABEH, A.; SCHAERER, J.; YOUNG, M.M.; Fungal glucoamylases. Biotechnology Advances, v.24, p.80-85, 2006.

NOY, Y.; SKLAN, D. Digestion and absorption in the young chick. Poultry Science. v.74, p.366-373, 1995.

NOY, Y.; SKLAN, D. Uptake capacity in vitro for glucose and methionine and in situ for oleic acid in the proximal small intestine of posthatch chicks. Poultry Science, v.75, p.9981002, 1996.

NUNES, I.J. Nutrição animal básica. $2^{a}$ ed. Belo Horizonte: FEP-MVZ EDITORA, 1998. $388 \mathrm{p}$.

PHILIPS, S.M.; FULLER, R. The activities of amylase and a trypsin-like protease in the gut contents of germ-free and conventional chickens. British Poultry Science, v.24, p.115$121,1983$.

PRITCHARD, P.J. Digestion of sugars in the crop. Comparative Biochemistry and Physiology, v.43, p.195-205, 1972. 
SAVORY, C.J.; MITCHELL, M.A. Absorption of hexose and pentose sugars in vivo in perfused intestinal segments in the fowl. Comparative Biochemistry and Physiology - Part A: Molecular \& Integrative Physiology, v.100, p.969-974, 1991.

SIBBALD, I. Passage of feed through the adult rooster. Poultry Science, v.58, p.446-459, 1979.

SKRABANJA V.; KREFT, I. Resistant starch formation following autoclaving of buckwheat (Fagopyrum esculentum Moench) groats an in vitro study. Journal of Agricultural and Food Chemistry, v.46, p.2020-23, 1998.

UNI, Z.; NOY, Y.; SKLAN, D. Post-hatch changes in morphology and function of the small intestine in heavy and light strain chicks. Poultry Science, v.74, p.1622-1629, 1995.

VAN der MAAREL, M.J.E.C.; VAN der VEEN, B.; UITDEHAHG, J.C.M.; LEEMHUIS, H.; DIJKHUIZEN, L. Properties and applications of starchconverting enzymes of the a-amylase family. Journal of Biotechnology v.94, p.137-155, 2002.

VIEIRA, S.L.; PENZ Jr, A.M.; METZ, M.; POPHAL, S. Reassessing sodium requirement for the 7-day old broiler chicken. Poultry Science, v.79, p.196-202, 2000. 